\title{
Las Obras Novelescas de Martín Luis Guzmán
}

$\mathbf{E}$ NTRE los escritores contemporáneos de México, se destaca, por la importancia de su obra, Martín Luis Guzmán. Sus antecedentes, su carácter y su vida le han preparado para ser el historiador por excelencia del período revolucionario del siglo veinte en su país. Nació en Chihuahua el 6 de octubre de 1887, siendo sus padres el coronel Martín Luis Guzmán, profesor del Colegio Militar de Chapultepec, y doña Carmen Franco Terrazas. En virtud de la oposición terminante del coronel Guzmán a que su hijo emprendiera la carrera militar, la educación de éste tomó un rumbo distinto. Después de hacer sus estudios primarios en Tacubaya y en Veracruz, cursó el bachillerato en la Escuela Nacional Preparatoria de la capital e ingresó luego en la Escuela Nacional de Jurisprudencia de la Universidad de México. Sin embargo, su obra fundamental había de desarrollarse en los campos de la política, del periodismo y de la literatura.

La inclinación de Guzmán hacia el periodismo se manifestó bien pronto, pues a la temprana edad de catorce años fundó en Veracruz un periódico quincenal juvenil titulado La Juventud: En 1908 empezó a dedicarse en serio al periodismo, entrando a formar parte de la redacción de El Imparcial, periódico importante de la capital. Desde 1914 hasta 1934 -excepción hecha de tres años-Guzmán vivió desterrado, principalmente en Nueva York y en Madrid. Durante un corto periodo, en el año 1917, fué profesor de lengua y literatura 
españolas en la Universidad de Minnesota. En todo este tiempo - alrededor de veinte años-no dejó de dedicarse al periodismo y a la literatura. En 1917 dirigió en Nuevá York la revista mexicana $E l$ Gráfico y colaboró en otras publicaciones castellanas de aquella ciudad. En 1920, de regreso en México, fué nombrado jefe de la sección editorial de $E l$ Heraldo de México, periódico fundado por el general revolucionario Salvador Alvarado. En 1922 fundó El Mundo, diario de la tarde, el cual tuvo una vida efímera a caúsa de una nueva expatriación de Guzmán al año siguiente de su aparición. Después de pasar otro año en Nueva York, el expatriado se trasladó a Madrid, donde vivió hasta 1934, siendo redactor, colaborador, editorialista y director de varios periódicos madrileños, entre ellos $E l$ Sol y $L a V o z$. En la actualidad es colaborador de El Universal de México. Tiene en preparación para la prensa varios tomos que recogerán lo principal de sus escritos literarios y políticos dispersos ahora en los periódicos.

La vida política de Guzmán empezó en el año 1911 con el nombramiento de delegado para la Convención Nacional del Partido Liberal Progresista. Allí hizo sus primeras armas como orador y político. Con extraordinario entusiasmo se afilió a la causa de don Francisco I. Madero, causa que no abandonó nunca. Entre aquel grupo de jóvenes idealistas, resueltos a reformar la vida política de su patria según las normas de la verdadera democracia, Guzmán es de los que permanecen fieles a sus ideales, llenos de confianza y optimismo en cuanto al porvenir de su país.

Durante el período que precedió al asesinato de Madero, y en particular durante los "diez días trágicos" antes del golpe militar del 22 de febrero, 1913, Guzmán, con otros partidarios del gobierno, dedicó todas sus energías.al apoyo de la causa de la legalidad; por conducto del periódico El Honor Nacional, se dedicó a informar al público sobre la verdad de lo que pasaba y a denunciar un día $y$ otro la intriga $y$ las maniobras de algunas misiones diplomáticas confabuladas con los elementos reaccionarios que acaudillaban los generales Mondragón y Félix Díaz.

Triunfante el crimen y consumada la usurpación de Victoriano Huerta, Guzmán abandonó la capital y fué a unirse 
a los revolucionarios del Norte. Sus dos tentativas de llegar a Sonora, narradas en El águila $y$ la serpiente, constituyen toda una odisea. Al lograr finalmente este propósito, se dedicó con entusiasmo a la causa de.la revolución antihuertista. Habiendo prometido a su padre-muerto en 1910 - que nunca sería militar, Guzmán se negó siempre a aceptar las comisiones militares que se le ofrecían. Actuó como revolucionario civil con las fuerzas del general Ramón F. Iturbe en Sinaloa y con las del general Obregón en Sonora; luego pasó a Chihuahua con el Primer Jefe del Ejército Constitucionalista, Venustiano Carranza. En plena guerra supo Guzmán obtener ventaja para su causa de sus dotes de escritor, aun cuando no se dedicaba especialmente a la propaganda. Su misión fué la de plasmar en realidad concreta la trayectoria confusa del pensamiento revolucionario, reorganizando: los hospitales militares, realizando viajes a los Estados Unidos con el propósito de lograr su neutralidad, trabajando por conseguir el levantamiento del embargo sobre las armas y logrando así comprar municiones, ambulancias $\mathrm{y}$ abastecimientos para los hospitales. Quizá no sea el menor entre sus servicios el de haber moderado al rústico Pancho Villa, sobre el cual, en una ocasión, influyó para que perdonara la vida a ciento sesenta prisioneros.

Al sobrevenir las primeras dificultades que separaron al villismo del carrancismo, Guzmán, convencido de que Carranza sólo aspiraba a ser otro Porfirio Díaz, optó por la facción villista. Sirvió bajo las órdenes de Francisco Villa hasta que Carranza le encarceló en la Penitenciaría del Distrito Federal en septiembre de 1914, en unión de Manuel Bonilla, Luis G. Malváez, Carlos Domínguez, Abel B. Serratos, José Ortiz Rodríguez y otros villistas. En noviembre del mismo año fué puesto en libertad por la Convención Militar de Aguascalientes, convocada con el propósito de solucionar las diferencias entre Carranza, Villa y Zapata. Formado el gobierno convencionista con el general Eulalio Gutiérrez como presidente provisional, Guzmán fué a la capital en calidad de consejero del Ministro de la Guerra, a cuyo lado estuvo hasta el momento en que se produjo la ruptura entre Eulalio Gutiérrez y Francisco Villa. Esta ruptura puso a Guzmán en grave perplejidad, 
en la que se cruzaban por una parte su lealtad al movimiento revolucionario y por otra el afecto a Villa, el caudillo popular. Ante tan difícil situación deciđió expatriarse temporalmente. Sin embargo, el triunfo del carrancismo prolongó su ausencia por seis años, hasta 1920. En dicho año regresó a México y fué elegido diputado al Congreso Nacional. 'En el año 1923 el fracaso de la revolución de Adolfo de la Huerta le obligó a expatriarse de nuevo. Desde su regreso definitivo, en 1934, Guzmán se ha ocupado poco de la política. Ha sido - en diversas épocas - bibliotecario de la Escuela Nacional de Altos Estudios, secretario de la Universidad Nacional y director de la Biblioteca Nacional.

Quien desee comprender la segunda fase de la revolución mexicana - es decir, desde la muerte de Madero hasta el triunfo de Carranza- debe leer las obras de Guzmán El águila y la serpiente y las Memorias de Pancho Villa. En cuanto a las intrigas y maquinaciones del período Obregón-Calles, $L a$ sombra del caudillo constituye una excelente guía descriptiva.

La primera de las obras narrativas históricas de Guzmán, El águila y la serpiente, ha tenido un éxito extraordinario, estando actualmente en prensa su cuarta edición y habiéndose traducido la obra al inglés, al francés, al alemán, al holandés y al checo. La versión inglesa, por desgracia, fué tan resumida por los editores que ha perdido gran parte de su valor histórico y de su efecto artístico. Entre las traducciones, la alemana es la que el propio autor considera mejor realizada y la que ha obtenido mayor éxito de librexía y venta. La sigue en éxito y favor popular la edición francesa.

El águila y la serpiente no es, según el autor, una novela propiamente, pero los críticos y los bibliógrafos en general la clasifican así. Ciertamente el lector no enterado de la plena autenticidad histórica y la cuidadosa documentación de la obra no vacilaría en denominarla novela histórica. Tiene la descripción interpretativa, el diálogo natural, la caracterización penetrante, la narración viva y dramática y la continuidad de interés que entran en la composición de una buena novela. El porqué de estas cualidades salta a la vista y es que el autor vivió plenamente los dramáticos sucesos que relata. Aunque no se exhibe personalmente a través de las pági- 
nas de su libro, sino todo lo contrario, el lector siente hondamente la sinceridad y la realidad de cuanto escribe el autor. Escritor de profesión, durante todas sus experiencias revolucionarias reunía con cuidado la materia para sus futuros libros. Siempre con un cuadernito en el bolsillo, iba apuntando hechos, sucesos, impresiones, observaciones y notas sobre conversaciones, para ampliarlas después ordenadamente en sus ratos libres. Así, gran parte del libro fué escrito en el mismo sitio donde se realizaron los sucesos antes de que se esfumaran ideas e impresiones o pudieran borrarse de la memoria los detalles, las fechas y los nombres.

Por la forma en que está escrito, el libro pudiera ser considerado más bien como unas memorias que como una novela. Con una sola excepción, la imaginación no juega para nada en la composición del libro, aunque se utilizan en él elementos superiores a la imaginación - aun desde el punto de vista novelístico - tales como una minuciosa e inteligente observación $\mathrm{y}$ un análisis penetrante de caracteres, de motivos y de sentimientos. El único ejemplo de pura imaginación que contiene - y que por cierto no quita nada a la exactitud histórica-son los pensamientos del autor al contemplar con horror los mutilados del Hospital Militar de Culiacán. Imagina el autor que las balas tienen también fantasía y que gozan en infligir tan infinita variedad de heridas. Existen balas maliciosas, otras atrevidas, graciosas, deportivas, eficaces; algunas son alegremente dinámicas y las hay sencillamente diabólicas. Estas reflexiones nacieron, sin duda, de la jocosa referencia de Obregón a su propia "herida ridícula".

Quizá fuera desacertado calificar El águila y la serpiente como novela, ya que el autor mismo no incluye la obra en esa categoría. Sin embargo, en vista de que lectores y críticos la clasifican así, podría ser interesante indicar brevemente por qué no es una novela. En primer lugar, ningún personaje ni grupo de personajes domina la acción. Toman parte en la acción gran número de personas cuya intervención, en algunos casos, se termina en seguida, mientras en otros casos queda pendiente. El único personaje siempre presente es el autor o cronista, aun cuando esté silenciada más bien que subrayada su propia perșonalidad y su intervención en la intriga. EI 
protagonista del libro, como lo demuestra claramente el título, es el pueblo mexicano, caracterizado por las cualidades del águila y de la serpiente. En segundo lugar, la estructura no es la de una novela: muchos incidentes, narrados en-orden cronológicamente exacto pero no orgánicamente preciso, se unen plásticamente para formar el concepto de la conciencia política mexicana y de los elementos que originaron la ideología revolucionaria. Así es que, aunque no sobra ni un pasaje desde el punto de vista del propósito del autor, indicado en el título, sin embargo muchas relaciones podrían desglosarse por completo del contexto y considerarse como unidades aisladas y, por sí mismas, excelentes cuentos o short stories. Tales pasajes o capítulos, enumerados por sus títulos, son: "La bella espía", "La araña homicida", "La fuga de Pancho Villa", "La fiesta de las balas", "Un préstamo forzoso", "La muerte del gaucho Mújica", "El sueño del compadre Urbina" y "La muerte de David Berlanga". (1) Por cierto, y como puede verse por estos ejemplos y por los títulos de sus libros, Guzmán - sea por dón natural, sea por su práctica periodística- se revela como maestro en el arte de escribir títulos. Todos los cuentos nombrados son rigurosamente históricos. Guzmán no tuvo que inventar incidentes dramáticos, pues los tenía constantemente alrededor suyo. Su mérito consiste en haber acertado a darles la expresión literaria adecuada.

En el terreno histórico, el gran valor de El águila y la serpiente consiste en la pintura exacta de las personalidades y la ideología de la revolución y de la intriga política consumada tras la escena militar. Guzmán, por su profunda comprensión de la naturaleza humana, por su capacidad para evaluar y analizar los motivos políticos, por su identificación con la revolución desde su iniciación, por su formidable memoria fotográfica, por su claridad de expresión y por su carácter especial que atraía a los hombres revolucionarios y los animaba a expansionarse con él, ha podido mostrar todo el panorama de la segunda fase de la revolución. Vese a los militares de carrera frecuentemente postergados y hasta sacrificados por la envidia de los generales improvisados. Vese a los caudillos - grandes y pequeños, verdaderos y aspirantes-, a los idealistas teóricos — civiles y militares-, a los 
moralistas de hondas convicciones, a los bandidos revolucionarios, a los bajos aventureros...

Guzmán presenta la ideología de la revolución tal como fué en su segunda fase-muy obscura-y explica por qué cayeron en el olvido principios y propósitos. La bandera de Madero - sufragio efectivo, no reelección, reforma agrariaparecía ondear todavía, pero de hecho los propósitos principales de ahora eran vengar la muerte de "el Apóstol", arrojar al usurpador Huerta $\mathrm{y}$, en un sentido general, restablecer el gobierno constitucional. La cizaña, fomentada por Carranza con su táctica de "dividir y reinar", se reducía en el fondo a ". . la disputa, eterna entre mexicanos, de grupos plurales dispuestos a adueñarse del poder, que es singular: predominio en unos y otros, de las ambiciones inmediatas y egoístas sobre las grandes aspiraciones desinteresadas; equivocación del impulso mediocre que lleva a buscar el premio de una obra con el impulso noble de la obra misma". (2) Por pobreza de ideas y de principios, los caudillos se tildaron unos a otros de "radicales", "conservadores", "reaccionarios". Algunos de los líderes civiles y de los militares tenían un concepto claro de las miras políticas del movimiento: mantener el carácter original de la revolución establecido por Madero, es decir, democrático, impersonal, anticaudillesco. Se veía claramente que el liderìsmo de Carranza y de Obregón iba dirigido al más descarado caudillismo, con el objeto final de establecer una dictadura, y por tanto no les quedaba a los idealistas más esperanza que la dirección militar de Villa, campeón muy poco idóneo como portaestandarte de una revolución purificadora y regeneradora. ¿Era capaz Villa de supeditar su enorme fuerza al servicio de principios para él incomprensibles o no existentes? Los sucesos posteriores probaron que no lo era, y que sólo iría hasta donde él mismo claramente viera. Así se explica el fracaso de esta fase de la revolución y el retroceso al más nefasto caudillismo en la persona de Venustiano Carranza.

La siguiente obra de Guzmán, La sombra del caudillo (Madrid, 1929), también ha sido acogida con entusiasmo. Se han publicado de ella tres ediciones y se ha traducido al francés y al holandés. La sombra del caudillo es una novela histó10 
rica, un roman à clef, que muestra los peores aspectos del caudillismo en México, en el período Obregón-Calles. Para poder dar una descripción completa de esa plaga de la política mexicana y también para poder incluir ciertos sucesos y caracteres distintivos y dramáticos, el autor ha sintetizado la obra en dos épocas. La primera abarca los acontecimientos de los años 1923-1924, cuando Adolfo de la Huerta, candidato presidencial, dirigió un levantamiento pre-eleccional, teniendo la suerte de eludir una conspiración tramada para asesinarlo, y cuando el presidente Alvaro Obregón logró imponer, contra la voluntad del pueblo, la candidatura de su protegido, Plutarco Elías Calles, preparando así el terreno para su propia reelección cuatro años después. La segunda época comprende la campaña presidencial de 1928 , cuando los candidatos oposicionistas, los generales Arnulfo Gómez y Francisco Serrano, fueron asesinados, sufriendo la misma suerte el presidente єlecto Obregón antes de que pudiera ocupar la presidencia. La mayor parte de los acontecimientos de la novela son de la segunda campaña, aunque gran parte del fondo histórico sea de la primera. Por lo menos uno de los sucesos más importantes de la intriga ocurrió en el año 1923: el complot para asesinar a los diputados más destacados del Congreso Nacional. En la Encyclopaedia Britannica (3) puede leerse la descripción de este hecho rigurosamente histórico. Guzmán, por ser diputado al Congreso, conoció directamente los sucesos de 1923, y aun cuando los de 1928 se desarrollaron durante su destierro, tenía un conocimiento perfecto de los personajes principales que habían de intervenir en la acción.

Los lectores mexicanos pueden identificar con facilidad a cada personaje de la novela. El autor no vacila en corroborarlos, a pesar de que viven todavía algunos de ellos. "El caudillo" es el general Alvaro Obregón; Hilario Jiménez, el candidato imposicionista de la administración, representa al general Plutarco Elías Calles; Ignacio Aguirre, candidato de la oposición, cuyo asesinato constituye el clímax de la intriga, es el general Francisco Serrano, asesinado en 1928; Recalde personifica al líder obrerista Luis Morones, jefe actual de la Confederación de Obreros Mexicanos; el general Leyva, que se reserva sádicamente el placer de matar a Aguirre, es el 
general Arnulfo Gómez, mencionado anteriormente; Emilio Olivier representa a Prieto Laurens; el infame Manuel Segura es Jorge Carregha; Catarino Ibãñez, gobernador del Estado de México, es Abundio Gómez, y así sucesivamente todos los personajes, inclusive los secundarios, representan políticos de la época. Hasta la actriz española, amante de Aguirre, se puede identificar por su nombre y fué, en efecto, amante de Serrano.

El único personaje no histórico es Axkaná. El lector, sin embargo, no puede menos de ver en él algo del carácter y de la actuación del propio autor. Diputado recto, sincero y concienzudo, representa la pequeña minoría de políticos nacio- nales que permanecían fieles al ideario de la revolución $\dot{y}$ que, a pesar de la corrupción de la administración, mantenían su propósito de seguir normas honradas. Por contraste de carácter y opiniones, por su intervención en la acción y por sus conversaciones con los personajes principales - con Aguirre, sobre todo-Axkaná actúa en la novela como comentarista, aclarando y destacando los sucesos, las situaciones y los personajés. Sin Axkaná y sin la lealtad y el valor de Aguirre -hombre libertino y poco escrupuloso por otra parte- el ambiente de La sombra del caudillo sería intolerable por sus traiciones, su cinismo, sus orgías, sus crímenes sanguinarios, sus latrocinios y su absoluto egoísmo. Esto no quiere decir que los personajes sean todos o buenos o malos. En modo alguno: hay muchos perfiles suavizadores. A veces el lector siente que algunos de los actores de la tragedia son solamente víctimas del sistema político. Ello se aprecia particularmente en Aguirre, cuyo carácter encarna la rectitud de Adolfo de la Huerta y el profundo egoísmo de Francisco Serrano.

En La sombra del caudillo Guzmán se acredita como autor de una novela excelente. Aun sin el fondo histórico y sin la clave de los personajes, la obra tiene un gran valor como novela. Según el dicho popular, "no puede dejarse su lectura un instante". Por encima de la erudición y de la crítica, ésta será siempre la primera pruéba empírica de una buena novela. $\mathrm{Y}$ la segunda es: ¿ Siente uno al terminarla ganas de volver a leerla? De esta prueba también sale triunfante La sombra del caudillo. Dan ganas de releerla, no sólo para comprender por 
completo el problema del control militar sobre la política, sino también para estudiar a fondo el carácter complicado de Aguirre y profundizar en la intriga tan compleja y al mismo tiempo tan clara. En ello radica, desde el punto de vista puramente novelístico, el mérito principal de la obra. No hay interpelaciones, divagaciones ni intermitencias del interés. La acción marcha directa, acumulativa y acelerada hacia su momento culminante: la muerte violenta e injusta de un hombre inocente que fué arrastrado, y en contra de su voluntad, hacia el traicionero remolino de la lucha política por el poder.

El magnum opus de Guzmán - todavía sin terminar - son sus Memorias de Pancho Villa. De los diez tomos proyectados, ya se han publicado tres: El hombre y sus armas (1938), Campos de batalla (1939) y Panoramas políticos (1939). El cuarto tomo está ya en prensa, dos más están escritos, y para los cuatro restantes el autor tiene preparado el material. Guzmán piensa continuar las memorias hasta la muerte de Villa y terminar con un epílogo escrito en el mismo estilo villesco.

Las fuentes utilizadas por Guzmán para su obra monumental son diversas. El archivo del famoso guerrillero, que consta de apuntes, telegramas y otros documentos, fué puesto a su disposición por la señora Austreberta Rentería, viuda de Villa. Esta materia llenaria unas cincuenta páginas impresas en cuarto. Se han utilizado documentos históricos del archivo nacional y de algunos Estados. La "Hoja de servicios" de Villa, que él mismo, hallándose preso en Santiago Tlaltelolco, escribió para su propia defensa, no sỏlo sirvió para comprobar y ordenar fechas y hechos, sino que también proporcionó a Guzmán un modelo del estilo de Villa. Otra fuente-quizá la de mayor importancia-fué el conjunto de observaciones de Guzmán sobre Villa y conversaciones con él durante la época de la convivencia de ambos como revolucionarios. Al joven periodista le agradaba pasar las veladas con el guerrillero, conversador notable que poseía una memoria extraordinaria. Guzmán, que ya en aquella época se daba cuenta de la importancia de Villa y que tenía la intención de hacer uso literario de su figura y de su vida, obtuvo copiosos apuntes de sus conversaciones, ampliándolos en sus ratos libres. De este modo, frescas las impresiones, le fué fácil reproducir el 
estilo de Villa en la conversación y la narración. $\mathrm{Y}$ como nunca pensaba Villa que algún día "andaría impreso", como decía Sancho Panza, se dejaba observar y retratar con toda naturalidad. Gran parte de las Memorias - y lo mismo se puede decir de algunos trozos de El águila y la serpiente- es literalmente, palabra por palabra, la misma expresión de Villa. En "El sueño de Urbina", por ejemplo, del segundo libro, se reproducen sus propias palabras. Aduce Guzmán en su comprobación que recuerda claramente las actitudes, los gestos y los ademanes del narrador. La fuente final de la materia de las Memorias estriba en las conversaciones -durante un periodo que abarca muchos años y se extiende a la actualidad-con individuos que conocían y trataron a Villa.

La forma en que han sido escritas las Memorias - reportaje exacto, verificación concienzuda y documentación copiosa- las coloca en la categoría de historia fidedigna. Durante el largo período en que la obra se ha ido publicando por entregas en El Universal de México, no hubo que hacer ni una sola rectificación. Siendo temas tan apasionadamente discutidos la personalidad de Villa, su ideología y su conducta en la guerra, el hecho de que el público no encontrara materia rectificable, es garantía de autenticidad histórica. Asombra la cantidad de detalles en las Memorias. Cada uno de los centenares de personajes que encierran, por insignificante que sea, lleva su nombre verdadero, excepto en las contadas ocasiones en que dice 'Villa "de nombre que no me recuerdo". Cada hacienda, pueblo, rancho y ranchería, cada pico, cañón, arroyo y salto de agua puede ser fácilmente identificado por gente conocedora de las regiones descritas.

Al emprender las Memorias de Pancho Villa, Guzmán tuvo dos propósitos. El primero fué presentar un panorama de la revolución que aclarara esta fase de la lucha, a un tiempo tan decisiva y tan confusa. El segundo fué reivindicar la memoria de Pancho Villa. A su juicio, el Villa pintoresco de la leyenda, de los cuentos revolucionarios y de la pantalla no es el verdadero. Se han explotado hasta el infinito las cualidades destacadas y legendarias del valeroso guerrillero; al mismo tiempo el elemento conservador de México ha soslayado el lado serio de este hombre que fué en realidad un gran con- 
ductor. Guzmán considera a Villa como la única gran figura de la revolución, el único caudillo que fué siempre fiel al ideal básico del movimiento: la justicia social.

El Pancho Villa de las Memorias causa una impresión muy distinta de la del Pancho Villa de El águila y la serpiente - no en los rasgos principales de su personalidad, pero sí en cuanto a los aspectos en que es examinado. Esto ya de por sí revela la agudeza psicológica de Guzmán y su habilidad como escritor. El águila y la serpiente muestra la impresión que le causaba a un joven sensible, idealista y "de mucha civilización - como solía decir Villa-, el indomado "Bandido de la sierra". A medida que la vida avanza entre los dos, Guzmán comprende y estima más a Villa; sin embargo, el lector no puede evitar la sospecha de que la admiración sentida por el joven hacia el guerrillero dista muy poco de la que sentiría por un tigre en el interior de la jungla. Eșa impresión persiste hasta el mismo final del libro, donde Guzmán, en un conflicto entre las lealtades personales y sus convicciones políticas, se arroja "en la boca del lobo", sin saber si el desenlace será la vida o la muerte. En las Memorias, por el contrario, las reacciones de Guzmán no juegan para nada. Aparece sólo dos veces en los tres tomos indicados, como un personaje insignificante, tratado de un modo objetivo. Ha podido borrar por completo su propia personalidad, su cultura, todas las reacciones y los prejuicios de un hombre civilizado: en una palabra, se ha identificado con Pancho Villa. No es poco esto. El estilo de las Memorias es el de un hombre sencillo y rudo; el modo de razonar y juzgar es el de un bárbaro, si bien de convicciones y principios, cuyo carácter crece y se desarrolla bajo la pluma del autor. Las Memorias representan la auto-interpretación que hace Villa de su carácter, su vida, sus hazañas, sus creencias y sus aspiraciones. Para comprender esa interpretación, hay que partir de la premisa de que Villa era un hombre-fiera, amoral, y por lo mismo, bueno y malo por naturaleza. Todos sus actos, buenos y malos, obedecen meramente a emociones e instintos primitivos.

Aunque las extensas Memorias distan mucho de estar terminadas, los tres tomos publicados presentan un Pancho Villa interesante y digno de estudio. El hombre y sus armas, 
que empieza con Villa joven, de diecisiete años, abarca sus dieciséis años de bandido, sus varias tentativas de vivir una vida honrada, su ingreso en la revolución maderista el 17 de noviembre de 1910, su desarrollo como guerrillero, su ruptura con Pascual Orozco y su brillante campaña antiorozquista como general de brigada bajo las órdenes de Victoriano Huerta. Luego cuenta cómo Huerta, movido por los celos, le quiso matar y le encarceló en Santiago Tlaltelolco, de donde escapó Villa a los Estados Unidos y, consumado el asesinato de Madero, regresó a México, a la cabeza de ocho hombres, para unirse a la revolución antihuertista. Campos de batalla traza la carrera de Villa como jefe de brigada en la División del Norte, bajo el mando de Carranza, y su conquista del estado de Chihuahua y una parte de Durango. Abarca el período hasta el 2 de abril, 1914, fecha de la entrada triunfal de Villa en Torreón. Panoramas políticos describe el resto de la conquista del Norte y arializa las trágicas desavenencias entre los caudillos revolucionarios, sobre todo los motivos y el desarrollo de la ruptura entre Villa y Carranza.

Guzmán acepta como verídica la explicación que da Villa del por qué se situó fuera de la ley: por haber "puesto balazos" al hacendado que intentaba ofender a su hermanita Martina, de doce años. Villa, temeroso de las consecuencias de aquel acto, dada la posición e influencia del agredido, opt6 por dirigirse a la sierra, comenzando así su vida de aventura. Este suceso le llenó de amargura, amargura que creció después al convencerse Villa de la absoluta imposibilidad de volver a incorporarse a la vida normal: siempre le cortaban tal camino los ricos y los poderosos con las maquinaciones de "la llamada justicia". Villa llegó a odiar profundamente un sistema social que permitía tales injusticias. El momento decisivo de su vida fué cuando conoció a Abraham González, se enteró del programa justiciero de Madero y oyó por primera vez la palabra "patria". Entonces su odio amargo se transformó en la esperanza de un posible orden social mejor; su amor por las montañas y las barrancas se tradujo en devoción al ideal de una patria feliz y justa. Andando el tiempo, su programa rudimentario de " $\mathrm{A}$ abajo los ricos y arriba los pobres !" se desarrolló y plasmó en ideas más concretas y socia- 
les. Sin embargo, el principio básico nunca cambió: siempre creía y proclamaba que una parte de la riqueza del pais pertenecía por derecho y justicia a los que la producían por medio de su trabajo y que la revolución no tenía otra finalidad que la de establecer este equilibrio económico. A Villa le conmovía profundamente ver que Madero, hombre rico y privilegiado, se acordara de los pobres y deseara establecer la justicia social. Su devoción fanática al "Apóstol" no disminuyó al ver que éste no cumplía sus promesas: conocía el poder de las fuerzas reaccionarias que atábanle las manos al idealista. El vil asesinato de Madero inspiró en Villa un doble ideal: vengar la muerte del líder y continuar su obra de redimir a las masas de México. Villa hablaba poco de "libertad" y "democracia" - "la llamada democracia", solía decir. Evitando palabras y frases que le eran vagas se aferraba únicamente a la idea clara e inspiradora.

Como era de esperar en el caso de un hombre de instintos primarios y que carecía enteramente de cultura, un hombre cuyas circunstancias lo excluían de relaciones sociales normales y que concentraba todas sus energías en un solo propósito, las ideas y los principios de Villa fueron sencillos y rígidos. Para él no existían los matices: todo éra blanco o negro; los hombres - sobre todo los revolucionarios - eran o buenos 0 malos. El buen revolucionario era leal a Madero -0 a su memoria-, estaba resuelto a trabajar por el bien de los pobres y era "hombre de mucha ley".

Villa se creía firme e inalterablemente predestinado a fundar un régimen de justicia que redimiera de la miseria $y$ la. desesperación a las masas de México. Tal creencia le daba una fuerza moral enorme. Había en su carácter una mezcla extraña de dignidad y humildad que nunca degeneró en orgullo o en egoísmo. Al proclamarlo José Vasconcelos el gran héroe de la revolución, el comentario astuto de Villa fué “... sólo veía que aquel licenciado era enemigo del señor $\mathrm{Ca}$ rranza y hombre un poco hablador". (4) El hombre que amenazaba con "la justicia de Pancho Villa" y que era tan aficionado a las formas posesivas - "mis generales", "mis trenes", "mis hospitales", "mis victorias", "mis providencias"-anhelaba aprender siempre de aquellos que sabían más que él en 
Ios terrenos de la ciencia militar, de la literatura y del derecho internacional. De ello deriva gran parte de su fuerza, y por ello se explica la evolución del hombre analfabeta y violento en el gran general con silueta de estadista. En vez de mostrarse envidioso - como Carranza y Obregón- de los militares de carrera, Villa apreciaba sus conocimientos especializados, les pedía consejos, les tributaba honores y les hacía justicia. También en contraste con el arrogante y obstinado Carranza, Villa estaba dispuesto a aceptar los consejos que se le ofrecieran voluntariamente, con tal de que le parecieran razonables o iluminaran su ignorancia. Se sentía lo bastante grande para confesar sus errores y limitaciones y para rectificarlos siempre que fuera posible. En general, acataba toda autoridad superior - la de Huerta en la época anterior a la muerte de Madero y la de Carranza despuês de ser nombrado éste Jefe del Ejército Constitucionalista. Sin embargo, si estaba firmemente convencido de la superioridad de su propio juicio militar, no vacilaba en desatender otras órdenes. Los jefes nunca le perdonaron a Villa su falta de respeto aun cuando, como sucedía con frecuencia, sus actos de insubordinación trajeran como consecuencia victorias brillantes para la revolución.

Convencido de su alto destino, Villa se esforzaba constantemente en hacerse digno de su puesto de caudillo revolucionario. Despreciaba toda ocasión de enriquecerse, aunque lo permitiera a algunos de los suyos, porque “. . . a cada hombre, si es útil, hay que conservarlo contento, según la condición de su ánimo: al generoso por generoso, al voraz por voraz". (5) Dándose cuenta de que uno de sus grandes defectos como líder era el preferir la pistola a la razón, hizo esfuerzos prodigiosos por dominar su "carácter arrebatado", al cual se refiere con mucha frecuencia. Llegó a abstenerse de comer carne durante una temporada porque le había dicho cierto médico que tal privanza le ayudaria a contener sus ímpetus de ira.

De un modo especial, el Pancho Villa que describe Guzmán muestra un constante celo por conservar el carácter de la revolución, tal como él la entendía. Según Villa, siempre debía tenerse presente el ideal de la justicia social y no dejar nunca 
que ese ideal se malograra con egoísmos y ambiciones personales. Velaba cuidadosamente por el buen nombre de la revolución, evitando que sus ejércitos se desmandaran después de las batallas y cometieran saqueos desenfrenados. A veces, después de tomar una plaza, acuartelaba a los soldados para evitar abusos. Al posesionarse de una ciudad, cuidaba de nombrar en seguida un nuevo gobierno y de tranquilizar al público respecto del mantenimiento de la seguridad y el orden; se esforzaba en perturbar lo menos posible los negocios, visitaba los hospitales y daba ayuda a los pobres. Es verdad que trataba severamente a la quinta columna, pero siempre investigando previamente los casos, y solía proceder con justicia y aun a veces con misericordia. Igual celo mostraba Villa porque el prestigio y buen nombre de la revolución se reconociera en los Estados Unidos. Así por ejemplo, después de conquistar la ciudad fronteriza de Juárez, ejerció una vigilancia excepcional para que no se cometieran desmanes que tuvieran repercusiones más allá del río Bravo.

El sentido de responsabilidad de Villa se prolongaba y extendía a cada uno de sus "muchachitos". Según él, era justo que los que arriesgaban constantemente la vida en la guerra comieran $\mathrm{y}$ vistieran bien $\mathrm{y}$, hasta donde fuera posible, gozaran de la vida. Era cosa ya acordada que, ganada la guerra, ninguno de los revolucionarios sobrevivientes volviera a sufrir privaciones en su propia persona o en la de su familia. En las campañas, el primer cuidado de Yilla era evitar todo derramamiento inútil de sangre. Su servicio de ambulancias y hospitales era excelente, dadas las dificultades que existían para ello.

Una cualidad sorprendente en el carácter de Villa, tal como lo pinta Guzmán, es su sensibilidad extrema. Claro está que su profunda devoción a la causa popular era en él hija más del sentimiento que de la razón. Eso es evidente. Sin embargo, es sorprendente ver su admiración por la hermosura de la naturaleza y del hombre. Sumamente extraño es también verle llorar al vislumbrar el jacalito donde, y durante su ausencia, había muerto su madre; llorar también después de la batalla, por la muerte de sus soldados; llorar cuando Huerta le condenó a ser fusilado - y no por miedo, según lo 
explica Villa, sino por el dolor que siente al contemplar la ingratitud y la maldad de los hombres. En efecto, la característica menos comprensible del Pancho Villa de Guzmán es la facilidad que tiene para el llanto.

Fuera como fuese Villa como hombre, el militar Villa no inspira más que admiración. El estudio de sus campañas, tal como se describen en las Memorias, revela de modo indudable que era un genio militar, lo mismo en la táctica que en la estrategia. Su habilidad no se explica solamente por su apasionado fervor, ni por sus conocimientos del terreno adquiridos en los dieciséis años de vivirlos fuera de la ley, ni por su rapidez en asimilar los conocimientos técnicos de los militares de carrera. Por encima de todo ello, queda patente y acreditado que era un hombre dotado de extraordinarios dones naturales, dones cuyo valor se intensificaba por estar concentrados y canalizados en un solo fin.

La tragedia de la revolución de 1910-1920 fué el rompimiento sobrevenido entre Villa y Carranza. La causa de esta ruptura se aclara en las Memorias con más eficacia que en El águila y la serpiente. En opinión de Villa, Carranza se desvió del ideal puro de la revolución: bajo el mando de éste, el movimiento dejaba de ser una lucha por la justicia social y se convertía en una complicada partida entablada exclusivamente por el logro del poder político. Carranza, cuya obsesión era asumir la presidencia de la república, no podía tolerar un caudillo idolatrado por el ejército y las masas populares. Veía un rival en él. En esto Carranza desconocia y juzgaba mal a Villa: Villa no ambicionaba la presidencia. $\mathrm{Su}$ prodigioso sentido común le decía que no era ése su terreno: su misión era el aspecto militar de la revolución. No podía comprender Carranza que, si Villa se le oponía, exa sólo por defender su propio prestigio militar y proteger los principios de la revolución. Villa odiaba a los políticos "chocolateros y perfumados" que envolvían al Primer Jefe en una nube de adulaciones; no respetaba los conocimientos de Carranza y despreciaba profundamente su ambición y egoísmo. En Panoramas politicos se aprecia visiblemente cómo Carranza, progresiva y sistemáticamente, se esforzaba en anular a Villa aun con grave detrimento del éxito de la revolución. En cam- 
bio, Villa mostraba hacia su jefe enorme paciencia, sumisión e indulgencia. Dándose cuenta clara de que la única base firme para el triunfo de la revolución era mantener la unidad, sufrió-aunque en vano-innumerables humillaciones e injusticias.

Indudablemente el Pancho Villa de Guzmán es, para muchos de sus lectores, un personaje absolutamente distinto $\mathrm{y}$ nuevo. Quizá el autor haya idealizado excesivamente a su protagonista, encubriendo sus defectos y realzando sus virtudes, pero no obstante la obra de Guzmán es admirable y debe leerse con respeto por muchos motivos: entre otros, por su rectiutud de hombre $y$ de escritor, por su esmerada labor de documentación, por haber conocido con bastante intimidad a Villa y por haberse asociado a la revolución desde su iniciación hasta el año de 1915. Hay que reconocer, además, que esta crónica ofrece una explicación razonable del curso posterior de la revolución, sobre todo del lamentable fracaso de Carranza como reformador.

Gran parte del mérito de los tres tomos de las Memorias de Pancho Villa radica en su estilo literario. Dice Guzmán que le ha sido necesario un esfuerzo grande y continuado para sostener constantemente el modo de hablar y escribir de Villa. Ha acertado admirablemente al adaptar el lenguaje al carácter de su protagonista. Por ejemplo, la sinceridad y la sencillez de Villa quedan de manifiesto en su manera de emplear los nuevos vocablos y frases que va aprendiendo progresivamente: "...formación que llaman de línea desplegada", (6) "... lo que se nombra relaciones internacionales", (7) "... movimiento que llaman envolvente". (8) Lo admirable y acertado del estilo es sobre todo la sencillez, la gracia, la individualidad, el carácter popular, la naturalidad de la construcción, el sabor arcaico y la abundancia de datos geográficos y biográficos. En contraste con la mayoría de los escritores de la revolución, Guzmán evita en sus libros la obscenidad y la blasfemia que pudieran parecer naturales en el caso de un hombre como Villa. Tiene Villa innumerables expresiones predilectas que son muy pintorescas, como por ejemplo: hincapié en el sentido de pretexto, punto de vista de persecuciones por objeto de persecuciones, hacer una entrega en el sen- 
tido de hacer preso. Muy típicas de su personalidad y de su estilo son frases como: "tomé mis providencias", "le dije mis palabras", "se me revolvió toda la cólera de mi cuerpo", "hombre de mucha civilización", "hombre de mediana civilización", "hombre de poca civilización".

La obra predilecta de Guzmán son las Memorias; en ellas ha trabajado intensamente, durante un largo período de tiempo y con la mayor devoción. Aunque parezca paradójico, es su obra más original. Ya que las Memorias y El águila y la serpiente guardan estrecha relación cronológica - aunque los límites no sean los mismos-, el que quiera entender el período general a que se refieren debe leer las dos obras y compararlas. La segunda es más imparcial y objetiva, abarca varios puntos de vista, enfoca gran número de personajes revolucionarios prominentes, y aclara sus idearios y fines. Las Memorias, escritas sobre el leit motif de un solo revolucionario, siquiera sea el más importante de todos, es en realidad la explicación que da Pancho Villa - y la justificación que da Guzmán- del fracaso de la revolución de 1910-1920, la más sangrienta y la más prometedora de las revoluciones mexicanas.

Estas dos obras tienen la virtud de estar documentadas en alto grado y al mismo tiempo la de ser amenas como la más interesante novela. No son biografías noveladas, sino historia seria con los méritos de la literatura de imaginación. Con ellas Guzmán ha logrado un tipo literario de gran excelencia, tipo acaso único en las letras mexicanas. En ellas se combinan acertadamente los elementos meramente auténticos y básicos con los rasgos, trazos y estampas históricamente valiosos de toda buena novela realista.

Heien Phipps Houck,
Wellesley College, Mass.

(1) El águila y la serpiente, pp. 7-28, 116-122, 163-170, 171-181, 285-290, 311-316, 353-359. Madrid, 1928.

(2) Op. cit., p. 84.

(3) Edición de 1930, Addenda. 
(4) Campos de batalla, p. 192. México, 1939.

(5) Op. cit., p. 172.

(6) Op. cit., p. 101.

(7) Ibid., p. 71.

(8) Ibid., p. 38.

\section{BIBLIOGRAFIA DE LAS OBRAS NOVELESCAS DE MARTIN LUIS GUZMAN}

El aguila y la serpiente. M. Aguilar, Editor, Madrid, 1928.

El águila y la serpiente. $2^{*}$ edición. Madrid, Ciap., 1929.

La sombra del caudillo. Novela. Madrid, Espasa-Calpe, S. A., 1929.

La sombra del caudillo. Novela. $2^{3}$ edición. Madrid, Espasa-Calpe, S. A., 1930.

El águila y la serpiente. Primera parte. Esperanzas revolucionarias. $2^{2}$ edición. Madrid, Imp. J. Pueyo, 1931.

El águila y la serpiente. Segunda parte. En la bora del triunfo. $2^{3}$ edición. Madrid, Imp. J. Pueyo, 1931.

La sombra del caudillo. Novela. $3^{3}$ edición. Ediciones Botas. México, 1938.

L'aigle et le serpent. Traduction de Mathilde Pomès. Préface de Blaise Cendrars. Paris, J. O. Fourcade, 1930.

L'élection d'Axkaná González. Bifuzs, París, 1930.

L'ombre du caudillo. Traduit de l'espagnol par Georges Pillement. Paris, Libr. Gallimard, Eds. de La Nouvelle Revue Française, 1931.

The Eagle and the Serpent. Translated from the Spanish by Harriet de Onis. New York, Alfred A. Knopf, 1930.

Adler und schlange. Stuttgart, Engelhorn Knapf, 1932.

Avec Pancho Villa. París, Grasset, 1935.

In de schaduw van den Leider. Vertaald Door J. Slauerhoff en Dr. G. J.

'Geers. Den Haag, Boucher, 1937.

Kravvy Dest. Melantrich A. S. Praha, 1937. 